\title{
ENFRENTAR LOS DESASTRES SOCIONATURALES DESDE LOS CAPITALES Y RECURSOS COMUNITARIOS: EL CASO DE LA ERUPCIÓN VOLCÁNICA DE CHAITÉN, CHILE
}

\author{
JORGE A. LARENAS S. ${ }^{a}$, MARCELA A. SALGADO V. ${ }^{\text {b } ~}$ \\ XENIA S. FUSTER F.
}

\begin{abstract}
RESUMEN
El caso de Chaitén, en tanto expresión del modo de actuar de la política pública contemporánea frente a desastres socionaturales en Chile, resulta un buen ejemplo del desaprovechamiento por parte del Estado de los diversos capitales existentes al interior de pequeñas localidades donde aún operan esquemas de interacción social de tipo comunitario: redes de colaboración basadas en la confianza y reciprocidad (capital social); sistemas productivos basados en el conocimiento de los recursos territoriales (capital económico); población que reconoce sus tradiciones e identidades locales (capital cultural y simbólico).

Contrariamente, las agencias estatales irremediablemente actúan con esquemas estandarizados de corte centralista que operan con criterios distantes de las cosmovisiones presentes en los territorios alejados de los grandes centros urbanos que aglutinan a los tomadores de decisiones, lo cual provoca escasa oportunidad temporal, pertinencia sociocultural y eficacia en sus actuaciones.

Este artículo discutirá la relación entre sistemas de capitales comunitarios desde la perspectiva de Bourdieu, Durston, Arriagada, entre otros, y la política pública de gestión del riesgo; a partir del caso de Chaitén, se busca proponer recomendaciones de política pública que eviten impactos subjetivos, estructurales y políticos irreversibles. Todo esto en base a la indagación en discursos y prácticas por medio de la aplicación de entrevistas individuales y colectivas, así como la observación de algunas dinámicas organizativas en la población mencionada.
\end{abstract}

PALABRAS CLAVE: capital social, económico, cultural y simbólico, desastres socionaturales, políticas públicas.

a Investigador Asociado Centro de Investigación en Vulnerabilidades y Desastres Socionaturales (CIVDES), Académico Instituto de la Vivienda, Facultad de Arquitectura y Urbanismo, Universidad de Chile, Portugal 84, Santiago de Chile. jlarenas@uchilefau.cl

b Investigadora Joven Centro de Investigación en Vulnerabilidades y Desastres Socionaturales (CIVDES), Estudiante de Doctorado en Ciencias Sociales, Facultad de Ciencias Sociales, Universidad de Chile, Avda. Capitán Ignacio Carrera Pinto 1045, Nuñoa, Chile, salgado. marcela@gmail.com

c Académica Escuela de Trabajo Social, Facultad de Ciencias Sociales, Pontificia Universidad Católica de Chile. Coordinadora Observatorio de la Reconstrucción, Facultad de Arquitectura y Urbanismo, Universidad de Chile, Portugal 84, Santiago de Chile. xeniaff@uchilefau.cl 


\title{
FACING SOCIAL-NATURAL DISASTERS FROM CAPITAL AND COMMUNITY RESOURCES: OF CHAITEN VOLCANO ERUPTION CASE, CHILE
}

\begin{abstract}
The case of Chaitén, as expression of the contemporary public policy modus operandi in front of socio-natural disasters in Chile, is a good example of capital wasting by the state in inland small towns where community-based social interaction frameworks still operate: collaboration networks based on trust and reciprocity (social capital); productive systems based on knowledge of land resources (economic capital); population that recognizes local traditions and identities (cultural and symbolic capital).

In contrast, state agencies inevitably act under centralist frameworks, following standards distant from the world views present in areas that are away from large urban centers where decision makers are gathered; as a result there is limited temporary opportunity, sociocultural relevance and effectiveness in their actions.

This paper will discuss the relationship between community capitals systems from the perspective of Bourdieu, Durston, Arriagada, among others and risk management public policy; starting from Chaitén case, we seek to propose public policy recommendations that avoid irreversible subjective, structural and political impacts. The proposition is based on the observation of organizational dynamics in the above-mentioned population and on the inquiry into discourses and practices through the application of individual and group interviews.
\end{abstract}

KEY WORDS: social, economic, cultural and symbolic capital, social-natural disasters, public policies.

\section{INTRODUCCIÓN}

El 2 de mayo de 2008 hace erupción el volcán Chaitén, ubicado próximo a la ciudad homónima en la provincia de Palena de la Región de Los Lagos. Entre sus consecuencias se encuentra la inundación del sector por el desborde del río Blanco, formando un nuevo cauce que dejó a la ciudad dividida en dos: Chaitén Norte y Chaitén Sur (Ugarte \& Salgado, 2014). De esta manera una pequeña comunidad ${ }^{1}$ de colonos localizada en un magnífico entorno natural de la norpatagonia se vio confrontada a las consecuencias de la evacuación y desplazamiento hacia otras zonas urbanas de la misma provincia (Palena y Futaleufú), de la provincia de Chiloé (Ancud y Castro) y de la provincia de Llanquihue (Puerto Montt), lo que implicó de manera recurrente que el rendimiento de los activos acumulados a lo largo de sus trayectorias vitales perdieran su eficacia práctica y provocaran sentimientos de desarraigo (pérdida de puntos de referencia), incompetencia socio-laboral (carencia de habilidades para el desempeño en empleos urbanos) y pérdidas de sentido (malestar subjetivo).

Es decir, además del trauma asociado a la experiencia de vivir una erupción volcánica (explosiones ensordecedoras, violentos temblores y fumarolas) y verse en la obligación de abandonar improvisadamente sus viviendas y enceres (que son la manifestación material y tangible de sus proyectos de vida y por tanto no solo meros objetos "reemplazables" o "intercambiables"), el desplazamiento implica abandonar su hábitat y buscar azarosa y espontáneamente elementos "sucedáneos" para intentar recomponer sus activos en contextos desconocidos.

Entendemos que esto pone sobre la mesa la imperiosa necesidad de debatir sobre el carácter que deben adquirir las políticas públicas de gestión y enfrentamiento del riesgo para enfrentar con la adecuada pertinencia sociocultural las consecuencias de los desastres socionaturales, pues si bien se aprecia por parte de las agencias públicas una predisposición favorable para no escatimar recursos financieros y materiales para ponerlos al servicio de las comunidades afectadas, ello no

1 Al momento de la erupción, el área urbana de Chaitén alcanzaba una población de aproximadamente 6.000 habitantes. 
resulta suficiente para contener los efectos en los proyectos de vida de los sujetos individuales y colectivos que en este caso habitan en una localidad como Chaitén que parecía ofrecerles singulares condiciones de seguridad ontológica.

Precisando el enfoque conceptual que sustenta este trabajo, es oportuno indicar que se comprenderá por desastre natural la alteración del medio natural que tiene su origen en la combinación de amenazas naturales con fragilidades territoriales. Por otra parte, adherimos a la denominación de desastres socionaturales, pues entendemos que su incremento se origina a partir de decisiones que atañen a las sociedades, puesto que la exposición a las amenazas no son naturales. (Vargas, 2002).

Cabe señalar, además, que no todas las amenazas naturales afectan a todas las poblaciones por igual, por lo tanto, no todos los desastres socionaturales tienen el mismo potencial de impacto. Dentro de aquellos que generan consecuencias más dañinas en las comunidades que los sufren, se encuentran los tsunamis, los terremotos, las erupciones volcánicas y las inundaciones; pues al ser imprevistas, repentinas, desatarse en pocos segundos y ser poco predecibles, afectan psicosocialmente más que otras catástrofes (Bankoff, 1999).

En el análisis se identifica también la capacidad de adaptación que desarrollan las comunidades para enfrentar la catástrofe a través del aprovechamiento de sus propios recursos. Para ello se recurre a la perspectiva de la estructura de oportunidades y activos (Cutter \& Emrich, 2006).

Para poner en contexto el caso de Chaitén, es preciso referir a la apreciación generalizada de sus habitantes respecto a su relación con el Estado de Chile, la cual se puede calificar de débil, inestable, distante y de escasa influencia en la configuración del territorio y sus poblados [“(...) no, porque nunca el Estado chileno ha estado en las zonas australes, son los colonos que llegaron a hacer patria, y aqui se quedaron (...) fueron nuestros abuelos quienes construyeron el pueblo" (Dirigente social, Chaitén, 2012)], apreciación que se radicaliza al momento del desastre ["Aquí tenemos que agradecer a Argentina, porque Argentina para salir no nos pidió carnet, no nos revisó, sino que dejó salir todo. Incluso, autorizó a salir camiones cargados con animales, sin desinfectarlos, sin nada, era salir, que la gente saliera rápido, entonces lo que no hizo el gobierno chileno. El Gobierno chileno siempre nos puso trabas, y Argentina fue el primero en llegar a Futaleufú con agua, porque el problema de nosotros también fue el agua, Argentina fue el primero en llegar con el agua" (Dirigenta social, Chaitén, 2013)].

Otras referencias recurrentes que plantean los chaiteninos respecto al abandono en el que se encontraban antes del desastre tienen que ver con la deficiente conectividad con los principales centros urbanos dotados de servicios de mayor complejidad y ello se resuelve con bastante frecuencia en el propio territorio norpatagónico y particularmente en la localidad de Esquel en el sector argentino, lo que acrecienta la percepción de abandono por parte del Estado de Chile ["Nosotros tenemos temporales, de repente para llegar a Chaitén son doce horas normales en las barcazas... (Desde Puerto Montt, la capital regional)... También podemos estar tres días en una barcaza porque el tiempo no nos deja llegar a Chaitén. Un problema de abandono del Estado chileno que hemos tenido por siempre" (Dirigenta social, Chaitén, 2013)]

El discurso crítico se profundiza cuando los chaiteninos se refieren a la erupción del volcán y la intervención del Estado en el manejo de la crisis, puesto que si bien ellos valoran la rapidez con la cual se actuó para evacuar a sus habitantes ante la eminente erupción, consideran que se tomaron decisiones improcedentes al no establecer una adecuada relación con los colonos (no realizando consultas para la toma de decisiones; no informando oportunamente). La noción de un Estado ausente y responsable del desastre: las acciones desde el Estado tienden a omitir los conocimientos y prácticas locales, omisión que es significada por la comunidad identificando al Estado como responsable del desastre ["Porque aqui a nosotros no nos hizo daño la naturaleza, el que nos hizo daño fue el Estado chileno, porque no se hubiera desbordado el río, porque ellos viajaban a cada rato al volcán (...) Entonces nosotros aqui en Chaitén no le podemos echar la culpa a la naturaleza, porque en Chaitén no cayeron más de 10 centimetros de ceniza (...) aquí fue el Estado el culpable de lo que sucedió" 
(Dirigente social, Chaitén, 2012)]

Para abordar el análisis, hacemos una breve referencia a las actuaciones del Estado tras la erupción volcánica y organizamos el trabajo en torno a las distintas fases de la catástrofe, como lo son la emergencia y evacuación, el desplazamiento y el retorno y reconstrucción del poblado. A su vez, conceptualmente pondremos énfasis en las perspectivas del capital social recurriendo a los trabajos de Bourdieu, Durston, Arriagada.

En cuanto al material analizado, el equipo interdisciplinario del Centro de Investigación en Vulnerabilidades y Desastres Socionaturales (CIVDES), realizó un trabajo de campo que contempló visitas a las ciudades de Chaitén y Puerto Montt, entre los años 2012 y 2013; entre las diversas técnicas e instrumentos aplicados durante el trabajo de campo, este artículo se basa en las siguientes: 1) dos talleres con habitantes que al momento de la erupción se encontraban viviendo en el área urbana de Chaitén, siendo posteriormente evacuados $y$ que al momento de los talleres se encontraban en proceso de retorno, en total participaron 11 vecinos/as; 2) 3 entrevistas individuales a funcionarios públicos del gobierno local (Alcalde, Encargado de la Dirección de Desarrollo Comunitario y Director de Obras de la Municipalidad de Chaitén); 3) entrevistas individuales a 5 dirigentes de organizaciones sociales que al momento de las entrevistas habían retornado a Chaitén y; 4) entrevistas individuales a 4 personas que al momento de la entrevista aún se encontraban en situación de desplazados en la ciudad de Puerto Montt. Se analiza además el relato de una dirigente social que participó del SeminarioTaller Internacional "Desastres Socionaturales y Vulnerabilidad social" organizado, en abril de 2013, por el CIVDES. El material obtenido fue trabajado mediante análisis de contenido, identificando categorías vinculadas a la activación y pérdida de capitales y recursos comunitarios según las etapas del desastre.

\section{CAPITALES Y RECURSOS COMUNITARIOS SEGÚN ETAPAS DEL DESASTRE}

Como se mencionó anteriormente, se analizará el desastre-socionatural ocurrido en Chaitén a partir de la identificación de los capitales y recursos con los que cuenta la comunidad. Al respecto, Arriagada (2006) señala que el fortalecimiento de los capitales en las poblaciones empobrecidas, en especial para aquellas que están en una constante situación de vulnerabilidad ante riesgos naturales, es clave para mejorar su situación y capacidad de resiliencia. De este modo, la autora reconoce cinco tipos de capitales, los que a su vez contienen tipos de activos: humano (que refiere a los activos propios de esta condición: conocimiento, salud, etc.), social (que contiene activos que refieren a las relaciones entabladas con otros y/o participación en organizaciones, las que facilitan el acceso a otros recursos) productivo o económico (activos físicos y financieros), natural (activos de calidad y cantidad de recursos naturales a los que se tiene acceso) y cultural (activos relacionados con los recursos y símbolos que se posee al ser parte de una cultura). De modo tal que, para acceder a estos recursos se ponen en juego las instituciones y estructuras sociales que afectan a su acceso y las formas en que las personas los transforman, reproducen y acumulan. Ambos elementos se ven afectados en una situación de catástrofe, donde las instituciones y estructuras redefinen la forma en que están interviniendo en los recursos, y donde las personas, familias y comunidades despliegan otras estrategias de transformación, reproducción y acumulaciónliberación de los recursos.

A partir de una amplia lectura de otros autores que han trabajo y desarrollado el concepto de capital social (entre ellos Putman, Durston, Bourdieu), la autora hace precisiones respecto de algunos conceptos claves que están involucrados en el capital social. El primero de ellos son las relaciones sociales, en tanto suponen lazos de confianza y reciprocidad que permiten o facilitan la resolución de problemas; un segundo aspecto es la relación conflicto/armonía, donde el capital social no sólo necesita de armonía sino también de conflictos, los que permiten una constante renovación y reproducción; un tercer concepto es la participación social en tanto el capital social necesita proyectos o iniciativas de bien común; en cuarto lugar reconoce el empoderamiento, lo cual implica un control de los recursos colectivos; quinto está la asociatividad, la que se hace necesaria para el capital social en tanto supone que las organizaciones sientan sus bases en la cooperación; por último, y lo ya mencionado anteriormente, son las redes 
sociales las que permiten ampliar el acceso a los recursos. A partir de esta conjunción de elementos es que el capital social se define como un "un recurso intangible, que permite a las personas y grupos la obtención de beneficios por medio de las relaciones sociales dotadas de confianza, reciprocidad y cooperación" (Arriagada, 2006, p. 12).

Con base en lo anterior, se presenta a continuación un análisis de los recursos y capitales activados en cada una de las fases del desastre, identificadas a partir del relato de los/as habitantes. Estas etapas son significadas por sus protagonistas y se encuentran marcadas por una serie de acciones y omisiones desplegadas por el gobierno central, el gobierno local y la propia ciudadanía. Las etapas así identificadas corresponden a: emergencia y evacuación; el desplazamiento y el retorno y reconstrucción de la ciudad (Ugarte \& Salgado, 2014).

\section{Estrategias de Sobrevivencia en la fase de Emergencia-Evacuación}

El 7 de mayo de 2008, los tribunales de la Décima Región acogieron el recurso de protección presentado por la Intendencia, ordenando el desalojo de la zona afectada por la erupción. Acogido este recurso, Carabineros procede a la evacuación inmediata y obligatoria de los habitantes de Chaitén que se resistían a salir del radio de 30 kilómetros dispuesto por la autoridad.

Junto con la evacuación de la población, Chaitén es declarado en "Estado de Catástrofe"2, lo que, entre otras cosas, se traduce en restricciones a la circulación de la población, a las libertades de trabajo, información y reunión. Aspecto importante a relevar considerando que en contextos de catástrofe la población recurre principalmente a sus recursos sociales (principalmente redes de apoyo) y comunitarios para enfrentar el trauma y recomponer su vida cotidiana al momento del shock (Imilan et al. 2015), por cuanto el hecho que se limiten las

2 Para declarar en estado de catástrofe una zona afectada u otra que lo requiera como consecuencia de la calamidad producida, el P. de R. requiere: a) que se produzca una calamidad pública (terremoto, avalancha, epidemia, etc.) en algún lugar del país y b) el acuerdo del C.S.N. (Arts. $40 \mathrm{~N}^{\circ} 4$ y $96-$ e). El estado de catástrofe significa, de acuerdo al Art. $41 \mathrm{~N}^{\circ} 5$, que el Presidente de la República libertades, en específico las que atañen al campo de lo social, puede impactar aún más a la población afectada.

Según lo expuesto por Ugarte y Salgado (2014), es posible indicar que la acción estatal supuso diversos mecanismos para enfrentar la emergencia en Chaitén. En una primera etapa de la emergencia, las autoridades deciden evacuar por completo a la población, lo que se realiza principalmente por barcazas hacia Puerto Montt y Chiloé, ubicando a las personas en albergues temporales durante 2 meses, transfiriendo bonos en dinero para enfrentar adecuadamente su condición de desplazados y posteriormente otorgar subsidios de vivienda (Marchant, 2010). Esto último estando asociado a la compra de viviendas de los damnificados en Chaitén (Ley 20.385: Ley Chaitén, Gobierno de Chile). Al respecto, el informe "Diagnóstico del estado reconstrucción", elaborado por el Ministerio del Interior y Seguridad Publica (2014), señala que en abril del 2009 se habrían entregado 23.463 bonos para las familias evacuadas de Chaitén. Entre los bonos entregados se contemplaron: subsidios para el pago de arriendos y gastos de consumos básicos (gas, electricidad, agua, etc.); bonos de manutención por familia, dependiendo del tamaño del grupo familiar; bonos por cada integrante de la familia con edad menos o igual a 18 años (y máximo 24 años si se encontraba estudiando) reconocido como carga familiar del Jefe de Hogar; y bonos para todos aquellos mayores de 24 años con algún tipo de discapacidad (Contraloría General de la Republica 2010).

Sin embargo, a pesar de la ayuda recibida, la evacuación es significada por la población como el "comienzo de la tragedia" (Ugarte \& Salgado, 2014), debido principalmente a la dispersión territorial de las familias y la disgregación de la comunidad chaitenina en diversas localidades:

“(...) Entonces por ahí parte un poco eh, creo yo (...). Por el hecho de que se disgrega la población, sin importar, una de las cosas

tiene la facultad, de restringir la circulación de las personas y el transporte de mercaderías; restringir las libertades de trabajo, de información, de opinión y de reunión; disponer requisiciones de bienes y establecer limitaciones al ejercicio del derecho de propiedad; y adoptar todas las medidas extraordinarias de carácter administrativo que estime necesarias. 
que nos llamó siempre la atención: fue sin importar si el grupo familiar se disgregaba o no. Eso jamás interesó. De hecho, cuando nos sacaban, nos empezaron a sacar de Chaitén, no les importó sacar a la mamá con los hijos, o solamente los hijos. Se permitía en un comienzo que solamente subieran las mujeres, los hombres no podían subir. Entonces yo creo que por ahi parte la tragedia, digamos" (Dirigente social, Chaitén, 2012).

Lo anterior da cuenta de que, a pesar de la importancia que puede tener en una catástrofe la restitución de la vida cotidiana, y la tendencia de las comunidades a organizarse y apoyarse principalmente en los grupos familiares (Imilan et al. 2015), el proceso de evacuación de Chaitén no considera los modos de vida tradicionales de la comunidad, por cuanto dispersa y divide a las familias, lo cual es considerado como un hito de inicio en la tragedia. En este contexto, se observa que es el mismo Estado quien es significado como responsable de la tragedia (Ugarte \& Salgado, 2014; Imilan et al. 2015; Larenas, 2015). Al respecto, Bourdieu (2001) y Arriagada (2006) señalan que el capital social tiene un valor en sí mismo por facilitar el acceso a otros recursos. En el análisis de este recurso, se releva el rol que las redes sociales juegan en él, en tanto éstas "se estructuran y reestructuran para conservar o aumentar los recursos" (Arriagada, 2006, p. 7). En contextos de catástrofes, las redes sociales juegan un rol fundamental, en tanto estas se activan, re-activan, ordenan, re-ordenan, distribuyen y re-distribuyen, debido a que, según sea el contexto, la población tiene altas demandas y muy específicas, por cuanto las formas en que pueden acceder a diversos recursos están determinadas principalmente por los flujos de redes sociales que alli convergen. Esto último también lo deja de manifiesto Larissa Lomnitz (1980) al preguntarse sobre cómo sobreviven los marginados, señalando que éstos están en una constante situación de emergencia y sobrevivencia, los que efectivamente sobreviven gracias a la movilización de los vínculos y redes sociales que construyen y permiten acceder a diversos recursos.

Es así como, de acuerdo al relato de las personas entrevistadas, se identifica en esta etapa la activación de recursos familiares y comunitarios, acciones principalmente relacionadas con ayuda en hospedaje y apoyo emocional al momento de la evacuación.; ejemplo de lo anterior se refleja en el siguiente relato:

"Bueno mi casa, mi casita en ese tiempo era más chiquitita, sirvió de albergue para varias familias. Cuando empezó todo. La gente esperando un tsunami...se venía pa la parte más alta...Entonces aqui se abrieron las dos puertecitas que tenía y estuvimos dos días con las puertas abiertas: la gente entraba, salia, entraba, salía. Después, en la evacuación, yo llegué a Castro. Yo afortunadamente tenía unos parientes ahí, asi que pude...al menos yo tuve dónde llegar" (Dirigente Social, Chaitén, 2012).

Estos planteamientos también los deja de manifiesto Lomnitz (1980) al señalar que los principales vínculos y redes sociales los establece la familia y quienes constituyen el vecindario. Esto también lo respalda Durston quien define al capital social como un "conjunto de normas, instituciones y organizaciones que promueven la confianza y la cooperación entre las personas en las comunidades y en la sociedad en su conjunto" (Durston, 1999, p. 103), pues ésta facilita la constitución de actores sociales o incluso la de formar sociedades civiles saludables. En este sentido, el capital social puede aducirse a los casos de transacción, producir bienes públicos y facilitar la constitución de actores sociales. Es en este contexto que el autor le da especial énfasis a la construcción de capital social comunitario para superar la pobreza y la exclusión.

De modo tal que el capital social comunitario implica que las instituciones contribuyan ("informalmente") al bien común, siendo éste una forma de institucionalidad social, es decir, no se constituye como un recurso individual. Este capital está conformado por normas, prácticas, y relaciones interpersonales existentes y observables, las que determinan cómo funcionan las organizaciones. Asimismo, el concepto de reciprocidad es central al paradigma del capital social comunitario (Durston, 1999; Contreras, 2000). Éste se refiere a las relaciones entre las instituciones formales e informales a nivel de la comunidad, es decir, cómo se interrelacionan dichas instituciones con las organizaciones comunitarias, que en el caso de Chaitén se observa 
cómo la organización familiar se constituye como una institución, la que no es necesariamente formal, y que a través de ella se re-articulan y conforman otras organizaciones con fines comunes. Es en este contexto que la comunidad de Chaitén también levanta acciones para enfrentar el riesgo, desde el periodo de evacuación hasta el presente (Ugarte \& Salgado, 2014; Ugarte et al. 2015), lo que se expresa en la creación de organizaciones vecinales de apoyo a los desplazados y comités de vivienda, que dialogaban con la Delegación Presidencial respecto de las acciones del Gobierno Central.

Sin embargo, a pesar del fortalecimiento de los lazos, esta etapa se reconoce como un proceso difícil por la incertidumbre respecto al tiempo que duraría la evacuación, el destino desconocido de familiares $y$ amigos $y$, en algunos casos, por no contar con redes de apoyo en los lugares de destino. Al mismo tiempo, uno de los elementos que más parece afectar a los chaiteninos son los impactos en los capitales económicos. Éstos son relevantes en tanto "los diferentes tipos de capital pueden obtenerse con ayuda del capital económico, pero sólo al precio de un mayor o menor esfuerzo de transformación, que resulta necesario para producir la forma de poder efectiva en el campo correspondiente" (Bourdieu, 2001, p. 157), de modo que los diversos capitales pueden traer consigo capital económico, así como hay otros elementos que se pueden conseguir sólo con los otros capitales.

“(...) A mi me echaron de mi trabajo, salimos... me echaron de mi trabajo, a mi hermano también, quedamos sin pega, de repente la gente nos miraba mal porque... de los castreños, $u$ otras personas: "es que a ustedes les están dando un bono, les están dando un bono" y ¿tanta rabia porque nos estaban dando un bono? ¡Ya! Me están dando un bono, pero por este bono que me están dando, si usted quiere yo se lo doy, pero usted me da su casa, me da su auto, me da su trabajo, me da el puesto de sus niños en la escuela, me pasa sus amigos también, y me pasa todo, todo lo que usted tenga, todo, todo, ¡ah no! Entonces se daba media vuelta y se iba" (Entrevista grupal, Chaitén, 2012)

Podría sostenerse que los chaiteninos, en mayor o menor medida, disponían de una acumulación equilibrada de capitales que operaban situacionalmente, es decir, operaban en el contexto particular del territorio en el cual habitaban. Al tratarse de una pequeña comunidad emplazada en un entorno rico en recursos naturales, permitía la relación entre sujetos que ponían en mutua disposición sus recursos generando relaciones de intercambio basadas de modo importante en la colaboración y la solidaridad. Es preciso consignar, además, el hecho de que se trata de una capital provincial y por ese hecho dispone de un cuadro institucional-público (con relativa independencia de la condición socioeconómica, comparten un sistema educacional y de salud público) que pone necesariamente en diálogo a los miembros de la comunidad. Sobre esto cabe destacar dos elementos a nuestro juicio significativos en la configuración de una comunidad chaitenina, al menos en lo que refiere a sus antiguos habitantes: se conocen desde siempre y por ello disponen de imaginarios y representaciones compartidos respecto a Chaitén, a la vez que sus trayectorias -múltiples y diversas- se entrecruzan permanentemente siendo un claro ejemplo de ello lo que ocurre actualmente en la Escuela Juan José Latorre a la que concurren todos los niños de Chaitén y por tanto se encuentra una proporción significativa de los miembros de la comunidad chaitenina, incluyendo los hijos de las principales autoridades públicas y de algunos empresarios locales. De esta manera, la eventual escasa disponibilidad de capital económico se ve compensada por un capital social de alta rentabilidad que permite dinamizar intercambios de tipo económico (aunque no necesariamente expresado en dinero). Es por ello que tras el desplazamiento la mera asignación de subsidios, que si bien aporta a aumentar el capital económico, no alcanza a cubrir los intercambios de bienes y servicios que tienen los chaiteninos, en especial en el territorio al que son desplazados puesto que por el hecho de no disponer de otros capitales, sus proyectos vitales dependen de manera principal precisamente de la disponibilidad de capital económico y, como ya se ha mencionado, carecen de otros capitales para que éstos puedan movilizar flujos financieros adicionales.

La Fig. 1 presenta imágenes que dan cuenta del proceso de evacuación de la población, la que se realiza principalmente por vía marítima, en distintos horarios y teniendo como destinos principales Puerto 


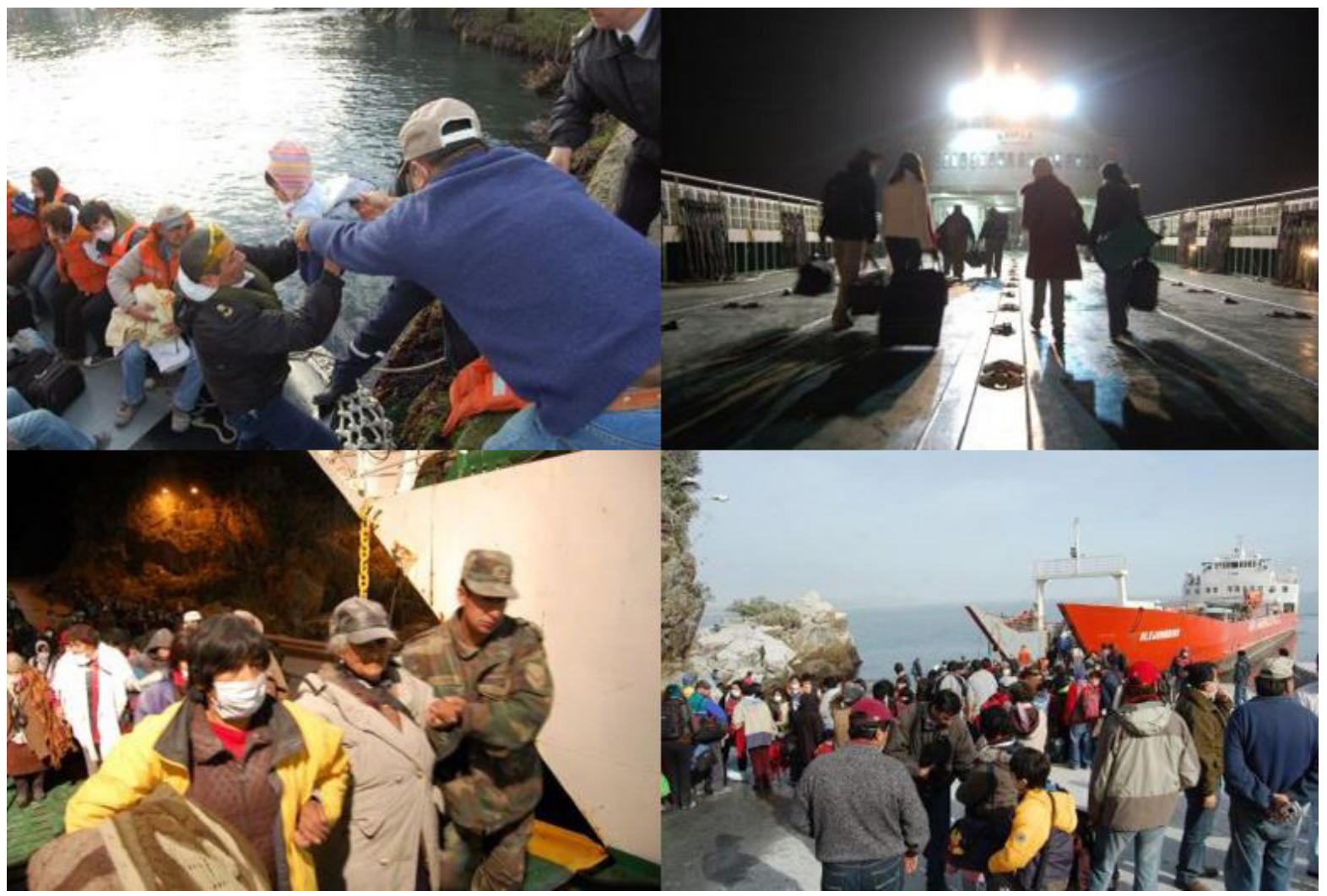

Fig. 1. Proceso de evacuación marítima de la población Chaitenina.

Fuente: Fotografías de Christian Brown, publicadas en grafelbergnoticias.blogia.com, el 12 de mayo de 2008.

Montt y Castro.

\section{El desplazamiento}

De acuerdo al informe del Ministerio del Interior y Seguridad Pública, del Gobierno de Chile (2014), luego de la evacuación, los residentes de las zonas rurales volvieron a sus localidades, mientras que los habitantes de zonas urbanas quedan en calidad de desplazados asentándose principalmente en Dalcahue, Quellón, Castro y Puerto Montt. En las Fig. 2 y 3 se pueden observar los desplazamientos de la población, de modo que los destinos más importantes de la migración son, Chiloé (31,5\% del total de personas desplazadas), Puerto Montt (27,6\% del total de personas desplazadas) y Palena (15,5\% del total de personas desplazadas). El desplazamiento a estas localidades, que a pesar de estar geográficamente cercanas a Chaitén, no logra mitigar del todo el impacto que provoca en los chaiteninos el hecho de dejar un territorio que está intrínsecamente asociado a sus capitales acumulados, afectando como se señaló anteriormente, al capital económico, social comunitario, cultural (respecto de la identidad fuertemente arraigada) y también el natural, debido a que los recursos naturales a los que se tenía acceso previo al desplazamiento, también se modifican.

En este sentido, es posible sostener que el "espacio de vulnerabilidad" revelado por los desastres socionaturales adquiere su máxima expresión en el caso de las poblaciones que se ven forzadas a migrar de sus lugares de residencia, transformándose en "desplazados ambientales", término que designa a "quienes, por motivo de cambios repentinos o progresivos en el medio ambiente que afectan adversamente su vida o sus condiciones de vida, se ven obligados a abandonar sus lugares de residencia, o deciden hacerlo, bien sea con carácter temporal o permanente, y que se desplazan dentro de sus propios países o al extranjero" (OIM, 2007, p. 3). Al respecto, Rojas (2010), sostiene que las poblaciones 


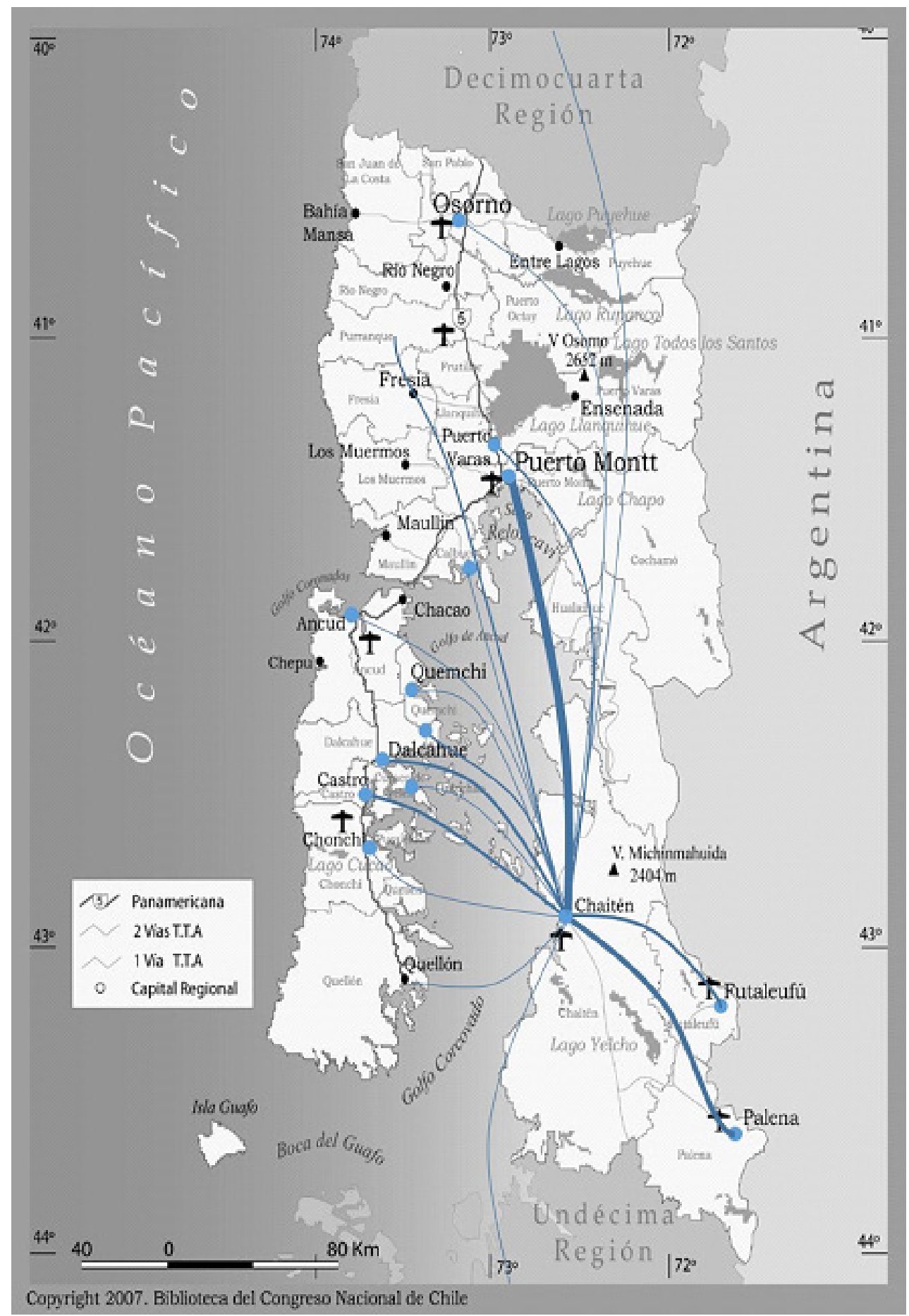

Fig. 2. Desplazados y principales localidades de destino.

Elaboración propia en base a datos de la Ilustre Municipalidad de Chaitén, 2011.

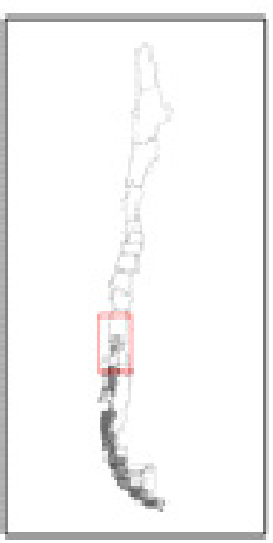

al ser desplazadas son ubicadas en un "no-lugar", el que representa la no vida, el desarraigo. En este sentido, el espacio vivido por un grupo social que lo reconoce como tal y se reconoce en pertenencia,

forma parte de una extensión territorial apropiada por quienes lo viven (Orella, 2010); convirtiéndose en elemento central en la constitución de los actores sociales y sus identidades (Arteaga, 2003). 


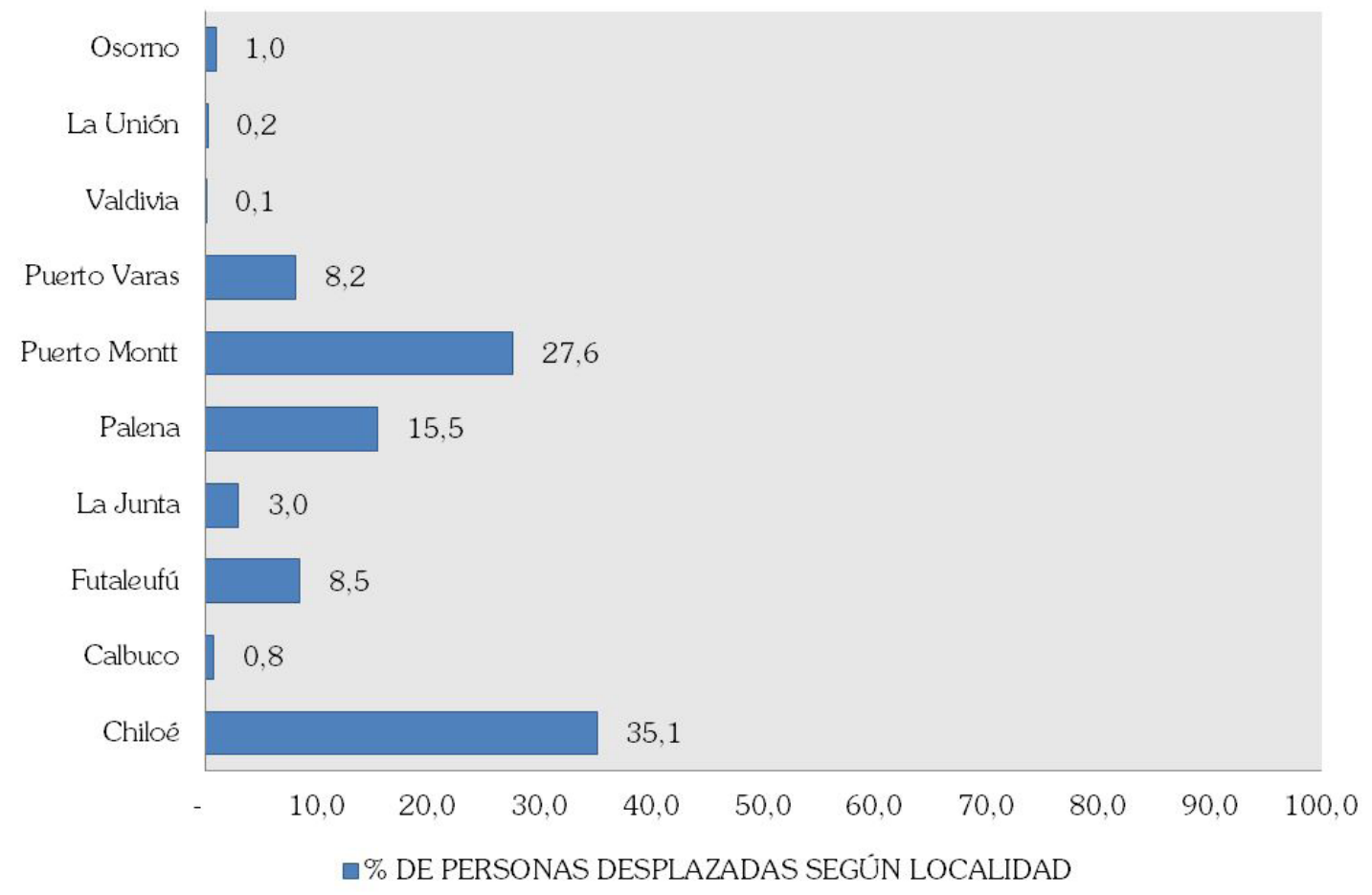

Fig. 3. Porcentaje de personas desplazadas de Chaitén.

Elaboración propia en base a datos de la Ilustre Municipalidad de Chaitén, 2011.

Todo esto puede afectar los niveles de participación de las poblaciones desplazadas debido a la pérdida de libertad para decidir sobre sus vidas (Sen, 2000), y a la alta dependencia que el Estado genera en ellos por medio de sus intervenciones, convirtiéndolos en ciudadanos asistidos.

De este modo, la etapa de desplazamiento es significada por los chaiteninos como un "exilio" proceso vivenciado $y$ significado como una imposición, marcado por la nostalgia y las dificultades de adaptación en las localidades de destino (Ugarte \& Salgado, 2014), tal como queda expresado en los siguientes relatos:

“(...) Nosotros siempre en Chiloé hablábamos del exilio, porque en el fondo el desplazamiento fue un exilio interno. $Y$ en realidad a la gente de Chaitén le fue muy difícil poderse ambientar en los lugares, incluso hay gente que se ha quedado y que es gente que nunca se ha acostumbrado en un pueblo (...) Entonces algunos pasaron muy bien en la época de las ayudas, otros tuvieron algunos problemas, especialmente de trabajo, pero la mayor parte no se acostumbra" (cartografía participativa, Chaitén, 2012)

"Porque Chaitén si bien es un pueblo joven, todo lo que tú quieras, hay mucha gente que tiene sus raíces acá, han vivido acá toda su vida, o sea no conocen otra cosa, ahora han salido afuera y afuera se han encontrado con un mundo que no es acogedor, no es acogedor como en este pueblo, tú en este pueblo tú dejas las puertas abiertas de tu casa (...)" (Vecina Chaitén, Sector Sur, 2012).

Tal como se ha señalado anteriormente, luego de declarar la ciudad como inhabitable, el gobierno comienza a desplegar acciones de apoyo a los desplazados, las que consisten principalmente en bonos y subsidio para la vivienda, junto con la oferta de compra de las casas de los chaiteninos, al mismo precio avaluado antes del desastre (Ley 20.385: Ley Chaitén, Gobierno de Chile). Durante este periodo, el Gobierno anuncia la creación de una nueva ciudad para los chaiteninos, el Proyecto Santa Bárbara; sin embargo, ésta nunca se concreta y en abril de 2010, 
la nueva Administración anuncia oficialmente que las personas pueden retornar al sector norte de (Ugarte \& Salgado, 2014). Estas acciones son criticadas por la población que acusa el carácter fragmentado y contradictorio de la información entregada, la prohibición de entrar a Chaitén y una serie de irregularidades en la entrega de bonos y subsidios.

"Porque acá no se podía entrar, porque estaba como en estado de sitio para pasar. Estaba custodiado por los militares y por carabineros. Permanentemente estuvo así. Y a las personas que lo sorprendian transitando por la calle de Chaitén era como tomar a un delincuente, y lo tomaban y lo llevaban detenido. O sea tratando de volver a sus propias casas, eran tratados como ladrones" (Entrevista Grupal, Chaitén, 2012).

"Los beneficios nunca fueron estandarizados. Nunca se definió a quiénes sí y a quiénes no. Por lo tanto muchas veces la gente advirtió como arbitrario que otros dijeran: 'tú sí te vamos a dar bono, no a ti no te vamos a dar bono, entonces tú tienes subsidio, no tú no tienes subsidio.' Entonces nunca hubo una norma, cachai” (Entrevista Funcionario Público, Chaitén, 2012).

En esta línea, Ugarte \& Salgado (2014) señalan que estas acciones son significadas como "poco transparentes, como un engaño, ya que sostienen que hubo acuerdos y anuncios que posteriormente no se cumplieron (...) Además, la mayor parte de las personas sostiene que estas acciones no se realizaron en los tiempos adecuados, que no hubo información acerca de la oferta pública, que todo el proceso fue lento, que no existió un mecanismo claro de asignación de beneficios como bonos y subsidios, que el apoyo psicosocial fue insuficiente en relación a la cantidad de población afectada y a la magnitud del trauma" (Ugarte \& Salgado, 2014, p. 40-41)

Son todas estas acciones gubernamentales las que afectan las relaciones de confianza y reciprocidad entre los chaiteninos con el Estado (Larenas, 2015), consecuencia de los escasos espacios de participación y transparencia respecto de las decisiones y acciones que se emprendieron. En este sentido, Arriagada (2006) realiza preguntas orientadoras para las políticas públicasy su incorporación del capital social: ¿Se trabaja directamente sobre los activos de la población en todas las etapas de la catástrofe? ¿Cómo es el capital social que existe en los programas públicos y qué lo vincula con la población afectada? En el caso de Chaitén difícilmente se pueden responder integralmente. Es necesario poner en relieve que el esfuerzo desplegado por el Estado en ningún caso carece de rigurosidad técnica ni tampoco podría reprocharse la celeridad con la cual se actuó, pero al mismo tiempo hay que remarcar que dichas actuaciones estuvieron marcadas por excesivo centralismo, dogmatismo tecnocrático y verticalismo decisional que instala una brecha entre la actuación del Estado y las aspiraciones y expectativas de los chaiteninos (Larenas, 2015).

En esta etapa y en un escenario de desacople entre Estado y comunidad, es cuando más se evidencian acciones desplegadas desde la ciudadanía, donde se pueden ver los vestigios más claros respecto al potencial de asociatividad de la comunidad chaitenina, de modo que una vez pasado el shock del desastre, las acciones comunitarias se caracterizan por reivindicaciones ciudadanas en búsqueda del respeto de sus derechos (Ugarte et al. 2015), por cuanto es la conformación y desarrollo del capital social, basado en relaciones de confianza y reciprocidad en búsqueda de beneficios comunes, la clave en esta etapa, debido a que la ciudadanía formaliza su relación colectiva a través de la conformación de diversas organizaciones que permitan dialogar de manera institucional con el gobierno central y local.

"Nosotros formamos la agrupación de hijos de amigos de Chaitén, en Puerto Montt, cuando nos estaban pasando a llevar, a pisotear, y hacian lo que querían con nosotros (...) La junta de vecinos fue lo primero que se formó, o sea, hijos y amigos de Chaitén, ahí estábamos en el exilio. Después llegamos los doce rebeldes a Chaitén y formamos la Junta de vecinos" (Dirigente social, Chaitén, 2014).

"Entonces surge la organización social de los desplazados como una cosa natural para poder beneficiarse con lo que estaban entregando tanto el estado como los privados, que en Chiloé no llegaba mucho. Y desde ahí nosotros trabajamos bastante con las 
organizaciones. Organizamos en cada lugar donde había desplazados de Chaitén, una organización social y todas esas organizaciones después la agrupamos en una provincial (Vecino Chaitén, 2012).

"Nosotros hicimos unos cabildos en Ancud, Castro, Palena, Coyhaique con los Chaiteninos desplazados. Íbamos haciendo que nos contaran su historia, qué habian vivido, qué había significado para ellos, cómo se imaginaban su futuro" (Cartografías Participativas, Chaitén, 2012)

\section{El retorno-reconstrucción y}

la reestructuración del capital social latente

El año 2010 se anuncia oficialmente la posibilidad de retornar a Chaitén, específicamente al sector Norte de la ciudad. En la actualidad según informe del Ministerio del Interior y Seguridad Pública (2014) hay 1.732 personas habitando en Chaitén, 1180 en el Sector Norte y 552 en el Sector Sur. Al respecto, el informe señala: "En el sector sur, en el cual los estudios señalan que persiste el riesgo para las personas, el Estado a través de la Ley Chaitén, procedió a la expropiación de la mayor parte de las propiedades, que corresponden a desplazados. Actualmente hay familias que se encuentran en estos terrenos en calidad de "ocupas", en peores condiciones que las del Sector Norte, ya que la instalación de servicios es mínima" (Ministerio del Interior y Seguridad Pública, 2014, p. 9).

En la fase de retorno y reconstrucción, las principales acciones llevadas a cabo por las personas son la resistencia, entendida como el retorno y re-habitación de Chaitén por un grupo pequeño de personas a los 3 meses posteriores a la erupción, tratando de recuperar el territorio; la toma de algunas casas del sector sur por parte de varias familias, tras la oficialización de retorno, para poder regresar a Chaitén, la realización de eventos a beneficio para reunir dinero y comprar algunos implementos necesarios para habilitar la escuela o la posta, y la organización de agrupaciones para la reconstrucción. Manifestando, al mismo tiempo, una fuerte crítica al accionar del gobierno, señalando que no se encuentra preparado para llevar a cabo este proceso (Ugarte \& Salgado, 2014).

"Yo creo que en la emergencia se actuó muy bien. Yo creo que se actuó muy bien tanto en la evacuación como en el tratamiento mismo de la emergencia. Pero se... dilató mucho el tema de...de, del retorno y la reconstrucción que le llamaban, la segunda etapa. Porque el Estado, yo siempre digo que el Estado no está preparado para, el Estado no está preparado para atender una emergencia. No está preparado para atender el retorno y la reconstrucción" (Representante Gobierno Local, Chaitén, 2012).

En este sentido, el proceso es significado como "la nueva colonización", dando cuenta de una lucha entre el Estado y los ciudadanos retornados, por el repoblamiento y apropiación del territorio (Ugarte \& Salgado, 2014), demostrando desconfianza a la hora de ser intervenidos por el Estado, pues la toma de decisiones de manera central gatilla esta percepción de poca pertinencia de las acciones desarrolladas. Así mismo se busca la restitución de la vida cotidiana, donde se destaca la escasa presencia de las instituciones formales, y más bien se valora el rol del capital social y comunitario en la recuperación del territorio, vale decir, son los habitantes los que encuentran seguridades y recursos en ellos mismos, pero siempre desde una perspectiva colectiva.

“(...). Ahora se viene la nueva colonización territorial de este cuento $y$ normalmente los que han llegado son los chacanos $^{3}$, los que tienen un compromiso. No cualquier gente vive acá, hay que tener como un temple muy especial para vivir acá, en la colonización nuevamente, no todos son colonos" (Representante gobierno local, Chaitén, 2012).

"La única finalidad nuestra era recuperar espacios públicos perdidos, para volverlos a entregar a la comunidad. Y así recuperamos la escuela, recuperamos la posta, porque donde está funcionando la posta lo recuperamos nosotros. No lo hizo el servicio. Lo hicimos nosotros. Nosotros recuperamos

3 Por Chacanos se hace referencia a los colonos, los primeros pobladores que fundaron la ciudad de Chaitén. 


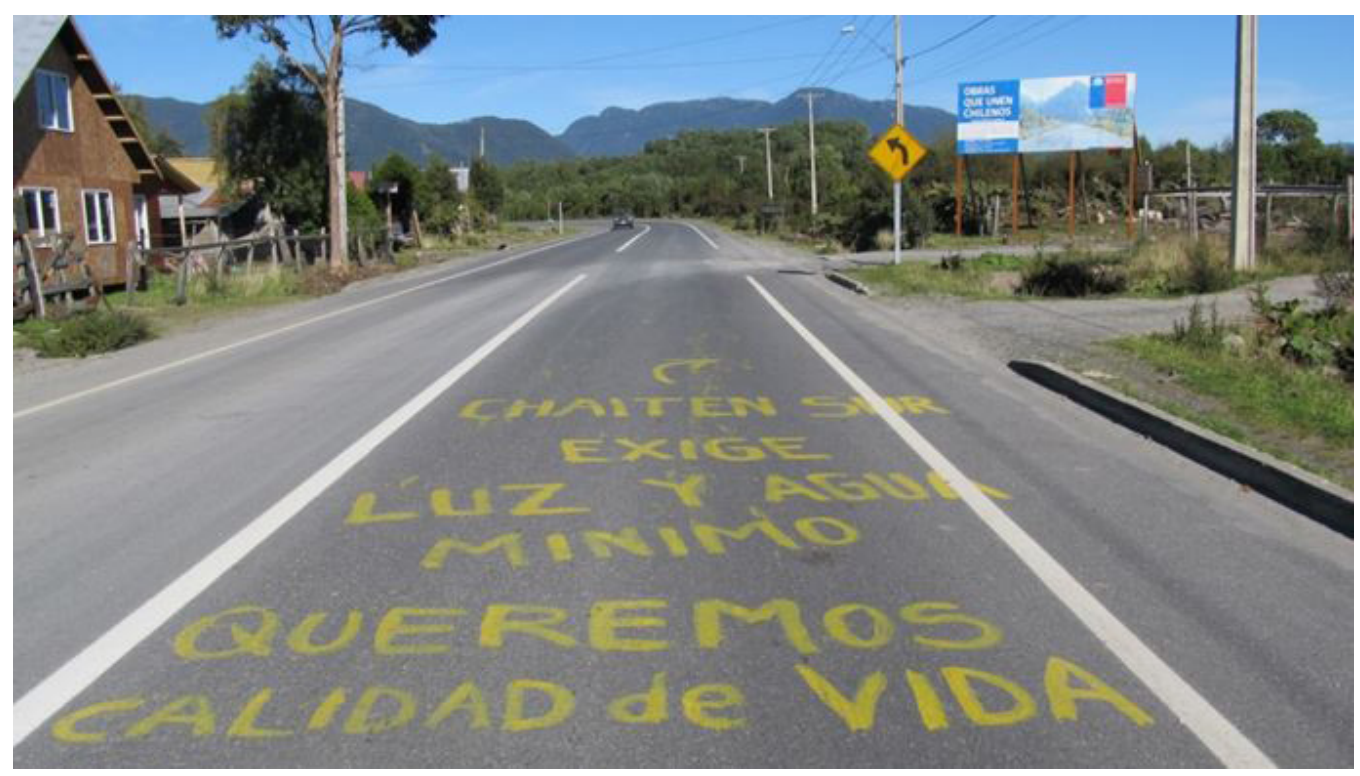

Fig. 4. Demandas de la población retornada. Fuente: Registro fotográfico Centro de Investigación en Vulnerabilidad y Desastres Socionaturales (CIVDES), 2012.

esa casa. Sí, nos agrupamos. Grupos de gente que arreglábamos las puertas, las ventanas, le poníamos cortinas, ahi le pusimos cama. Recuperamos unas camillas que estaban en la escuela por allá abajo, las trajimos pa acá. Los medicamentos los comprábamos nosotros. A mí me tocó conseguir medicamentos con una farmacéutica, una amiga en Chiloé... eh... y cosas asi po, o sea, la finalidad nuestra fue esa”. (Dirigente social, Chaitén, 2012).

"Para poder recuperar el único carro que quedaba en Chaitén, se tuvo que formar con puras mujeres habian 2 hombres, para poder recuperar ese carro, y hoy dia felizmente gracias a las mujeres de Chaitén el cuerpo de bomberos tiene como 4 carros que dicen gobierno regional, porque fueron ellas las que lucharon para conseguir los carros, porque Chaitén lo desarmaron completo. El estado se encargó de desarmar Chaitén completo, hoy dia no tenemos salud, tenemos una salud que es una casita que es la mitad de esto, y se llamaba, no es una posta es una estación de salud" (Dirigenta social, Chaitén, 2013).

En la Fig. 4 se da cuenta de una de las tantas manifestaciones de la población retornada que exige al Estado las condiciones mínimas para poder volver a habitar normalmente su territorio.

Todas estas tensiones que sitúan a la comunidad en una posición de resistencia ante el accionar del Estado, bien las explica Perea al señalar que "para los de abajo emerge de sus tradiciones portando un yo colectivo; para el pensamiento social encarna un vínculo, mientras que para el Estado dispone un instrumento útil a su proyecto de gobernabilidad" (Perea, 2006, p. 164). Según lo señalado por el autor es por las distintas (y en este caso disímiles) pretensiones de proyectos sobre un territorio que se desencadena el pensamiento colectivo y la construcción de vínculos en la comunidad, de modo que cabe reflexionar respecto de los efectos no esperados -pero beneficiosos- de la acción pública.

A modo de síntesis, es necesario poner atención en algunos elementos que ponen en cuestión los modos de actuación del Estado en escenarios de desastres socionaturales y que si bien en este caso remiten al caso de Chaitén, se trataría de prácticas recurrentes pues varias de ellas se han observado tras el terremoto del año 2010 (Imilan et al. 2015). El caso particular de Chaitén, tanto por su escala territorial como por su comunidad cohesionada y portadora de 
una fuerte identidad, sería un escenario bastante propicio para innovar en lo que refiere a la gestión y planificación del territorio, promoviendo coordinaciones intersectoriales para resolver de manera integrada los problemas y desafíos que enfrentan sus habitantes, todo esto en diálogo con las comunidades, sin embargo se aprecia una insistencia en enfoques sectoriales que fragmentan la realidad intervenida al proponer soluciones orientadas a resolver problemas singulares sin ponerlos en interrelación, muy ajustado por cierto a la premisa de la economía neoliberal "un problemaun instrumento". Lo anterior parece denotar una precaria reflexividad de la política pública para responder situacionalmente a los desafíos que la realidad le propone. En simple, más que ajustar sus instrumentos y dispositivos a la realidad, se simplifica y comprime la realidad para adecuarla a sus propias herramientas. Desde esa perspectiva, Chaitén parece leerse como una abstracción que soporta respuestas estandarizadas que han sido diseñadas para escalas urbanas mayores y que pueden provocar que la solución profundice los problemas o provoque otros nuevos.

\section{CONCLUSIONES}

Resulta apropiado proponer conclusiones en tres niveles o ámbitos: en primer lugar referidos al caso analizado de Chaitén; en segundo lugar en torno a la intervención en pequeñas comunidades aisladas afectadas por desastres socionaturales; y en tercer y último lugar, algunas referencias generales respecto de políticas públicas y gestión de riesgos.

Sobre el caso de Chaitén, es necesario detenerse en el aparente aislamiento respecto al Estado chileno (altamente centralizado), el cual se da en oposición a la integración de los territorios de la norpatagonia (alta movilidad entre islas y comunicación con poblados fronterizos). Es importante entonces hacer la distinción del aislamiento respecto a qué y quiénes, puesto que se reconoce el rol geopolítico de Chaitén en tanto punto estratégico de paso hacia el sur y punto de conexión hacia los pueblos interiores, integración que parece tener origen en los procesos de colonización del territorio: existe un importante flujo de población desde Chiloé y Argentina (esto explica en cierta medida la reactivación de lazos sociales al momento de la evacuación y desplazamiento). Se pone atención en este aspecto puesto que habitualmente se caracterizan como "aisladas" zonas que pueden disponer de condiciones de integración sustantivas si se las analiza en sus propios contextos territoriales y por ello la referencia constante a la distancia social, cultural, histórica y política de los habitantes de Chaitén con el Estado de Chile, podría ser leída también como una reivindicación de un territorio mayor que en este caso sería la norpatagonia que se integra también con Argentina. Esto es relevante al plantear el análisis desde los capitales y recursos con los cuales cuentan las comunidades y más aún si se ponen en perspectiva territorial, puesto que el aislamiento respecto de la Región de Los Lagos y del resto del país se relativiza al observarlo desde el territorio norpatagónico.

En lo que respecta a las pequeñas localidades aisladas afectadas por desastres socionaturales, se consigna que habitualmente se trata de comunidades altamente cohesionadas y por tanto poseedoras de capital social con un fuerte sentido comunitario y familiar y que habitualmente ello redunda en la dinamización del acotado capital económico disponible, es decir, las capacidades resilientes de dichas comunidades se basan precisamente en su capital social y por tanto las acciones tendientes a disgregar a los miembros de tales comunidades tienen como consecuencia la profundización de los efectos subjetivos del desastre y la aparición del malestar frente a las actuaciones del Estado. Esto se ve reafirmado con el también desastre socionatural ocurrido el 27 de febrero del año 2010, pues después del terremoto y tsunami, son las ciudades y localidades intermedias y pequeñas las que más se vieron expuestas a la desprotección estatal y por lo mismo demostraron importantes expresiones de capital social para enfrentar situaciones de catástrofe y posterior reconstrucción (Imilan \& Fuster, 2013; Imilan et al. 2015). Queda también en evidencia que en ocasiones la llegada del Estado a los territorios generó una ruptura en los procesos de capital social que se estaban desarrollando (Imilan et al. 2015)

Por último y como se pudo observar a lo largo del artículo, aún es un desafío para Chile incorporar en sus políticas públicas las dimensiones del capital social, económico, cultural 
y comunitario, especialmente cuando el Estado se ve enfrentado a contextos de catástrofes, contextos en los que principalmente prima la mirada tecnocrática, sin incorporar lo valioso que puede ser recoger los recursos de las comunidades $y$ potenciarlos en función de su calidad de vida. Especial cuidado se debe tener al momento de trabajar con desplazamiento de población, donde el funcionamiento de la vida cotidiana de las comunidades debe ser restituido, y ejecutar acciones sin contemplar los valores locales puede ir en desmedro de sus necesidades y expectativas. Sin duda que este es un desafío central para la institucionalidad que debe generarse en Chile para la gestión del riesgo.

\section{BIBLIOGRAFÍA}

Arriagada, I. (2006). Breve guía para la aplicación del enfoque capital social en los programas de pobreza. Santiago, Chile: Comisión Económica para América Latina y el Caribe, Naciones Unidas.

Arteaga, C. (2003). Espacio local, identidades y acción local colectiva en la ciudad de México. El caso de Ajusco Medio en la delegación Tlalpan. En P. Ramírez Kuri (Ed.), Espacio público y reconstrucción de ciudadanía (pp. 365-392). México: FLACSO.

Bourdieu, P. (2001). Las formas del capital. Capital económico, capital cultural y capital social. En P. Bourdieu (Ed.), Poder, derecho y clases sociales. Bilbao: Desclée de Brouwer.

Contreras, R. (2000). Empoderamiento campesino y desarrollo local. Revista Austral de Ciencias Sociales, 4, 55-68.

Cutter, S., \& Emrich, C. (2006). Moral Hazard, Social Catastrophe: The Changing Face of Vulnerability along the Hurricane Coasts. Annals of the American Academy of Political and Social Science, 604, 102-111.

Durston, J. (1999). Construyendo apital social comunitario. CEPAL, 69, 103-118.

González, M. (2011). Estudio del Impacto Territorial Ambiental generado por la Erupción del Volcán Chaitén. (Tesis de pregrado). Escuela de Geografía, Facultad de Arquitectura y Urbanismo, Universidad de Chile.

Imilan, W., \& Fuster, X. (Eds.). (2013). Terremoto y tsunami post 27F: El caso de Constitución, Arauco y Llico.
Observatorio de la Reconstrucción, Instituto de la Vivienda, Facultad de Arquitectura y Urbanismo, Universidad de Chile.

Imilan, W., Fuster, X., \& Vergara, P. (2015). Post-disaster reconstruction without citizens and their social capital Llico (Chile). Environment and Urbanization, 27, 317-326.

Larenas, J. (2015). Resistencia y territorio: El caso de Chaitén en la zona austral de Chile. En C. Arteaga, \& R. Tapia (Eds.), Desastres Socionaturales en Chile (pp. 117-130). Santiago: Editorial Universitaria.

Lomnitz, L. (1980). Cómo sobreviven los marginados. (4ta ed.). México: Siglo Veintiuno Editores.

Marchant, J. (2010). Lágrimas de ceniza: estudio cualitativo sobre la experiencia de los habitantes de Chaitén, asentados en las ciudades de la isla de Chiloé y Puerto Montt. Santiago: Universidad de Chile.

Ministerio del Interior y Seguridad Pública. (2 de mayo de 2014). Diagnóstico estado de la Reconstrucción Erupción volcán Chaitén. Gobierno de Chile.

OIM. (2007). Notas para las Deliberaciones: La Migración y el Medio Ambiente. Nonagésima Cuarta Reunión del Consejo, MC/INF/288.

Orella, J. (2010). Geohistoria. Lurralde: investigación y espacio, 33, 233-310.

Perea, C. (2006). Comunidad y resistencia: poder en lo local urbano. Colombia internacional, 63, 148-171.

Rojas, J. (2010). Vulnerabilidad social, neoliberalismo y desastres: sueños y temores de la comunidad desplazada/damnificada por el terremoto tsunami. Sociedad Hoy, 19, 113-140.

Sen, A. (2000). Desarrollo y Libertad. Buenos Aires: Editorial Planeta S.A.

Ugarte, A., \& Salgado, M. (2014). Sujetos en emergencia: acciones colectivas de resistencia y enfrentamiento del riesgo antes desastres; el caso de Chaitén, Chile. Revista INVI, 80,143-168.

Ugarte, A., Salgado, M., \& Fuster, X. (2015). Emergencia de sujeto político y experiencias de acción colectiva en desastres socionaturales: Análisis de los casos de Santiago, Constitución y Chaitén. En C. Aretaga, \& R. Tapia (Eds.), Desastres Socionaturales en Chile (pp. 131-150). Santiago: Editorial Universitaria.

Vargas, J. (2002). Políticas Públicas para la reducción de la vulnerabilidad frente a los desastres naturales y socionaturales. Santiago, Chile: CEPAL. 